\title{
Breakthrough invasive aspergillosis and diagnostic accuracy of serum galactomannan enzyme immune assay during acute myeloid leukemia induction chemotherapy with posaconazole prophylaxis
}

Claire Calmettes ${ }^{1}$, Frederic Gabriel ${ }^{2}$, Elodie Blanchard ${ }^{3}$, Vincent Servant ${ }^{4}$, Stéphane Bouchet $^{5}$, Nathanael Kabore ${ }^{6}$, Edouard Forcade ${ }^{1}$, Camille Leroyer ${ }^{7}$, Audrey Bidet ${ }^{8}$, Valérie Latrabe ${ }^{9}$, Thibaut Leguay ${ }^{1}$, Stephane Vigouroux ${ }^{1}$, Reza Tabrizi $^{1}$, Dominique Breilh$^{4}$, Isabelle Accoceberry ${ }^{2}$, Manuel Tunon de Lara ${ }^{3}$, Arnaud Pigneux ${ }^{1}$, Noel Milpied $^{1}$ and Pierre-Yves Dumas ${ }^{1}$

\footnotetext{
${ }^{1}$ Department of Hematology and Cell Therapy, University Hospital, F-33000 Bordeaux, France

${ }^{2}$ Laboratory of Mycology, University Hospital, F-33000 Bordeaux, France

${ }^{3}$ Department of Respiratory Diseases, University Hospital, F-33000 Bordeaux, France

${ }^{4}$ Pharmacy, University Hospital, F-33000 Bordeaux, France

${ }^{5}$ Department of Clinical Pharmacology, University Hospital, F-33000 Bordeaux, France

${ }^{6}$ Medical Information Department, University Hospital, F-33000 Bordeaux, France

${ }^{7}$ Department of Infection Control, University Hospital, F-33000 Bordeaux, France

${ }^{8}$ Laboratory of Hematology, University Hospital, F-33000 Bordeaux, France

${ }^{9}$ Thoracic and Cardiovascular Imaging Department, University Hospital, F-33000 Bordeaux, France

Correspondence to: Pierre-Yves Dumas, email: pierre-yves.dumas@u-bordeaux.fr

Keywords: acute myeloid leukemia; posaconazole; invasive aspergillosis; galactomannan enzyme immunoassay; sensitivity

Received: February 28, 2018

Accepted: May 07, 2018

Published: June 01, 2018

Copyright: Calmettes et al. This is an open-access article distributed under the terms of the Creative Commons Attribution License 3.0 (CC BY 3.0), which permits unrestricted use, distribution, and reproduction in any medium, provided the original author and source are credited.
}

\section{ABSTRACT}

Posaconazole prophylaxis has demonstrated efficacy in the prevention of invasive aspergillosis during prolonged neutropenia following acute myeloid leukemia induction chemotherapy. Antifungal treatment decreases serum galactomannan enzyme immunoassay diagnostic accuracy that could delay the diagnosis and treatment.

We retrospectively studied patients with acute myeloid leukemia who underwent intensive chemotherapy and antifungal prophylaxis by posaconazole oral suspension. Clinical, radiological, microbiological features and treatment response of patients with invasive aspergillosis that occurred despite posaconazole prophylaxis were analyzed. Diagnostic accuracy of serum galactomannan assay according to posaconazole plasma concentrations has been performed.

A total of 288 patients with acute myeloid leukemia, treated by induction chemotherapy, who received posaconazole prophylaxis for more than five days were included in the present study. The incidence of invasive aspergillosis was $8 \%$ with 12 $(4.2 \%), 8(2.8 \%)$ and $3(1 \%)$, possible, probable and proven invasive aspergillosis, respectively. Posaconazole plasma concentration was available for 258 patients. Median duration of posaconazole treatment was 17 days, and median posaconazole plasma concentration was $0.5 \mathrm{mg} / \mathrm{L}$. None of patients with invasive aspergillosis and posaconazole concentration $\geq 0.5 \mathrm{mg} / \mathrm{L}$ had a serum galactomannan positive test. Sensitivity of serum galactomannan assay to detect probable and proven invasive 


\begin{abstract}
aspergillosis was $\mathbf{8 1 . 8 \%}$. Decreasing the cut-off value for serum galactomannan optical density index from 0.5 to 0.3 increased sensitivity to $90.9 \%$. In a homogenous cohort of acute myeloid leukemia patients during induction chemotherapy, increasing the posaconazole concentration decreases the sensitivity of serum galactomannan assay.
\end{abstract}

\section{INTRODUCTION}

Treatment of acute myeloid leukemia (AML) is generally divided in 2 steps: induction and consolidation. This treatment has not been really modified for 40 years and most of the prognostic improvement came from supportive care and allogeneic stem cell transplant [1]. The standard regimen of AML induction chemotherapy is a combination of an anthracycline with continuous infusion of cytarabine. This treatment leads to a deep and prolonged neutropenia which is a classical risk factor of invasive fungal disease (IFD), mainly invasive aspergillosis (IA).

Establishing early diagnosis of IA is a major issue hampered by poor clinical signs and the difficulty of mycological documentation. The diagnosis is based on a set of arguments: host factor, clinical and radiological patterns and mycological criteria for assignment of possible, probable and proven IA, according to European Organization for Research and Treatment of Cancer/ Mycoses Study Group (EORTC/MSG) criteria [2].

Direct microbiological diagnosis is rare in immunocompromised patients, requiring the use of indirect test such as serum Galactomannan (GM) enzyme immunoassay whose optical density index (GM-ODI) values are correlated with fungal burden and Aspergillusrelated disease progression [3]. Relevance of this test in IA diagnosis is criticized but remained the corner stone of decision tree in the management of fever in neutropenic patient, particularly during AML induction chemotherapy before prophylaxis area. This relevance is questionable since 2006 and the use of posaconazole as antifungal prophylaxis to prevent IFD during the neutropenic period following AML induction chemotherapy.

The current study aims to describe the breakthrough IA despite antifungal prophylaxis by posaconazole in a large cohort of AML patients during the induction chemotherapy. Moreover, this homogeneous population allowed us to determine the diagnostic accuracy of serum GM-ODI according to posaconazole plasma concentration in this specific context.

\section{RESULTS}

\section{Characteristics of patients and treatments}

Five hundred and eighty patients were initially identified for evaluation. We included 288 patients according to flow chart (Supplementary Figure 1) with a median follow-up about 13 months (range 1;75).
Demographic and treatment characteristics of these patients are shown in Table 1. Briefly, median age was 62 years, $4.1 \%$ of non-IA and $17.4 \%$ of IA patients had a history of chronic respiratory disease. All patients received standard dose of cytarabine, with daunorubicin for $35.1 \%$ or idarubicin for $64.6 \%$ of patients, $4.5 \%$ of patients received high dose cytarabine as second course of treatment for primary induction failure. Regimens of first and second induction courses are detailed in Supplementary Table 1. Median duration of neutropenia $<$ $1 \times 10^{9} / \mathrm{L}$ and $<0.5 \times 10^{9} / \mathrm{L}$ was respectively 24 and 21 days for non-IA patients and 31.5 and 29 days for IA patients. Deep neutropenia with absolute neutrophil count lower than $0.1 \times 10^{9} / \mathrm{L}$ for at least 1 day occurred in $38.9 \%$ of nonIA patients and $47.8 \%$ of IA patients. Two-hundred thirtyseven patients $(83.8 \%)$ received granulocyte-colonystimulating-factor during induction.

\section{Antifungal prophylaxis}

All patients received posaconazole as prophylaxis treatment, with a median duration of treatment of 17 days (IQR 12.5-22, range 5;64). Posaconazole prophylaxis has been discontinued in $8(2.8 \%)$ patients for adverse events including 6 liver toxicities and in 124 (43\%) patients for empirical or curative antifungal treatment. Two hundred and fifty-eight patients had at least one posaconazole plasma dosage with a mean of 2.7 dosages by patient (range 1-9). We analyzed 701 posaconazole plasma concentrations. Considering the highest individual plasma concentration, median of posaconazole plasma concentration was $0.5 \mathrm{mg} / \mathrm{L}$ (IQR $0.3-0.8$, range $0.1 ; 2.4$ ) for the whole cohort but $0.46 \mathrm{mg} / \mathrm{L}, 0.32 \mathrm{mg} / \mathrm{L}$ and $0.18 \mathrm{mg} / \mathrm{L}$ in possible, probable and proven IA patients, respectively.

\section{Characteristics and factors associated with IA}

The overall incidence of possible, probable and proven IA was $8 \%$ (Table 2). Twelve patients had possible IA, characterized by clinical criteria without mycological or histological criteria. Among the 8 patients with probable IA, serum GM-ODI was $\geq 0.5$ in 7 patients $(87.5 \%)$ and GM-ODI in bronchoalveolar lavage (BAL) was $\geq 1$ in 4 patients among five patients tested. For the 3 patients with proven IA, the diagnosis of IA was made by lobectomy or bronchial biopsy. Among them, 2 had serum GM-ODI $\geq$ 0.5 and 2 had GM-ODI $\geq 1$ in BAL. Clinical, mycological and histological criteria used for EORTC/MSG $2008 \mathrm{sub}$ group assignment are described in Table 2. Median delay 


\begin{tabular}{|c|c|c|c|}
\hline & Total & Absence of IA-n (\%) & IA-n (\%) \\
\hline & $\mathrm{N}=\mathbf{2 8 8}$ & $265(92 \%)$ & $23(8 \%)$ \\
\hline \multicolumn{4}{|l|}{ Age (years) } \\
\hline Median (IQR) & $62(50-67.5)$ & $62(51.5-68.5)$ & $56(49.5-68)$ \\
\hline Range & $17 ; 83$ & $17 ; 83$ & $22 ; 73$ \\
\hline Male gender-n (\%) & $165(57.3)$ & $149(56.2)$ & $16(69.6)$ \\
\hline \multicolumn{4}{|l|}{ Performance status-n (\%) } \\
\hline $0-1$ & $219(76)$ & $204(77)$ & $15(65.2)$ \\
\hline$\geq 2$ & $59(20.5)$ & $51(19.2)$ & $8(34.8)$ \\
\hline Missing data & $10(3.5)$ & $10(3.8)$ & 0 \\
\hline \multicolumn{4}{|l|}{ Comorbidities-n (\%) } \\
\hline Chronic respiratory disease & $15(5.2)$ & $11(4.1)$ & $4(17.4)$ \\
\hline Serum creatinine $>1.3 \mathrm{mg} / \mathrm{dL}$ & $1(0.3)$ & $1(0.4)$ & 0 \\
\hline Cirrhosis & 0 & 0 & 0 \\
\hline Diabetes mellitus & $18(6.3)$ & $16(6)$ & $2(8.7)$ \\
\hline Host factor except neutropenia & 0 & 0 & 0 \\
\hline \multicolumn{4}{|l|}{ WBC (G/L) at diagnosis } \\
\hline Median (IQR) & $5(2.1-33.1)$ & $5(2.1-32.2)$ & $4.1(2-50.6)$ \\
\hline Range & $0.3 ; 269.2$ & $0.3 ; 269.2$ & $0.4 ; 134$ \\
\hline \multicolumn{4}{|l|}{ ANC (G/L) at diagnosis } \\
\hline Median (IQR) & $1.1(0.4-3.7)$ & $1.16(0.4-3.7)$ & $0.9(0.5-3.2)$ \\
\hline Range & $0 ; 81.6$ & $0 ; 81.6$ & $0 ; 12$ \\
\hline \multicolumn{4}{|l|}{ FAB classification-n (\%) } \\
\hline $0-2$ & $92(31.9)$ & $86(32.5)$ & $6(26.1)$ \\
\hline 3 & $19(6.6)$ & $19(7.2)$ & 0 \\
\hline $4-5$ & $68(23.6)$ & $62(23.4)$ & $6(26.1)$ \\
\hline $6-7$ & $24(8.4)$ & $20(7.5)$ & $4(17.4)$ \\
\hline No FAB classification & $85(29.5)$ & $78(29.4)$ & $7(30.4)$ \\
\hline \multicolumn{4}{|l|}{ WHO subtype-n (\%) } \\
\hline De novo & $230(79.9)$ & $213(80.4)$ & $17(73.9)$ \\
\hline Secondary & $58(20.1)$ & $52(19.6)$ & $6(26.1)$ \\
\hline MDS-related & $14(4.9)$ & $12(4.5)$ & $2(8.7)$ \\
\hline MPN-related & $20(6.9)$ & $19(7.2)$ & $1(4.3)$ \\
\hline tAML & $24(8.3)$ & $21(7.9)$ & $3(13)$ \\
\hline \multicolumn{4}{|l|}{ Cytogenetics-n (\%) } \\
\hline Favorable & $49(17)$ & $46(17.3)$ & $3(13)$ \\
\hline Intermediate & $180(62.5)$ & $166(62.6)$ & $14(60.8)$ \\
\hline Adverse & $59(20.5)$ & $53(20)$ & $6(26)$ \\
\hline
\end{tabular}




\begin{tabular}{|c|c|c|c|}
\hline & Total & Absence of IA-n (\%) & IA-n (\%) \\
\hline & $\mathrm{N}=\mathbf{2 8 8}$ & $265(92 \%)$ & $23(8 \%)$ \\
\hline \multicolumn{4}{|l|}{ Induction chemotherapy-n (\%) } \\
\hline Daunorubicin-based & $101(35.1)$ & $90(34)$ & $11(47.8)$ \\
\hline Idarubicin-based & $186(64.6)$ & $175(66)$ & $11(47.8)$ \\
\hline Other & $1(0.3)$ & 0 & $1(4.4)$ \\
\hline \multicolumn{4}{|l|}{ Reinduction chemotherapy-n (\%) } \\
\hline High-dose cytarabine & $13(4.5)$ & $8(3)$ & $5(21.7)$ \\
\hline \multicolumn{4}{|l|}{ Duration of ANC $<1 \times 10^{9} / \mathrm{L}$ (days) } \\
\hline Median (IQR) & $24(20.5-29.5)$ & $24(20.5-28.5)$ & $31.5(22-43)$ \\
\hline Range & $8 ; 59$ & $8 ; 52$ & $11 ; 59$ \\
\hline \multicolumn{4}{|l|}{ Duration of ANC $<0.5 \times 10^{9} / \mathrm{L}$ (days) } \\
\hline Median (IQR) & $21(18.5-27)$ & $21(17.5-27)$ & $29(23.5-40)$ \\
\hline Range & $3 ; 51$ & $3 ; 49$ & $10 ; 51$ \\
\hline \multicolumn{4}{|l|}{$\mathrm{ANC}<0.1 \times 10^{9} / \mathrm{L}$} \\
\hline $\mathrm{n}(\%)$ & $117(40.6)$ & $103(38.9)$ & $11(47.8)$ \\
\hline Median duration (IQR) (days) & $8.5(3-14.5)$ & $8(3-14.5)$ & $11(7-23.5)$ \\
\hline Range & $1 ; 29$ & $1 ; 29$ & $2 ; 24$ \\
\hline Grade 4 mucositis-n (\%) & $28(9.7)$ & $23(8.7)$ & $5(21.7)$ \\
\hline \multicolumn{4}{|l|}{ Response to treatment-n (\%) } \\
\hline CR-CRi after first induction course & $223(77.4)$ & $220(83)$ & $16(69.5)$ \\
\hline CR-CRi after second induction course & $4(1.4)$ & $4(1.51)$ & 0 \\
\hline
\end{tabular}

IA: invasive Aspergillosis, WBC: white blood cell count, ANC: absolute neutrophil count, WHO: World Health

Organization, MDS: myelodysplastic syndrome, MPN, myeloproliferative neoplasm, tAML: therapy-related acute myeloid leukemia, FAB: French-American-British classification, IQR: Interquartile range, CR: complete remission, CRi: complete response with incomplete blood recovery.

from the beginning of chemotherapy to diagnosis of IA was 26 days (IQR 21-52, range 7;77). Median duration of absolute neutrophil count $<0.5 \times 10^{9} / \mathrm{L}$ was 25 days, 36 days and 44 days for possible, probable and proven IA, respectively. Clinical presentations were poor, but fever was constant, with inconstant cough, chest pain or dyspnea. Half of the patients were still febrile after 72 hours of antibacterial therapy and the other half became febrile after $48 \mathrm{~h}$ of apyrexia under antibacterial therapy. Computerized tomography (CT) scans were performed one or two days after the onset of symptoms. The most frequent CT signs were nodules with or without halo, ground glass opacities and alveolar consolidation. In univariate analysis, factors significantly associated with these 23 possible, probable and proven IA are described in Table 3. In multivariate analysis, factors associated with IA were previous history of chronic respiratory disease (OR 5.79, ${ }^{95 \%} \mathrm{CI}[1.51-22.24], \mathrm{p}=0.0105$ ) and duration of absolute neutrophil count $<0.5 \times 10^{9} / \mathrm{L}$ longer than 21 days (OR 4.34, ${ }^{95 \%} \mathrm{CI}$ [1.39-13.57], $\mathrm{p}=0.0118$ ) whereas patients with a posaconazole plasma concentration $>0.5 \mathrm{mg} / \mathrm{L}$ had a lower risk of IA (OR $0.22,{ }^{95 \%} \mathrm{CI}[0.07-0.67], \mathrm{p}=0.0082$ ) (Table 3). Treatments of IA are shown in Table 4. Twenty-two among the 23 IA patients received antifungal treatment with voriconazole whereas one exclusively received liposomal amphotericin B treatment. The 3 -month and one-year mortality rates were respectively $18 \%$ and $73 \%$ for the probable and proven IA, versus $5.3 \%$ and $18.1 \%$ in the non-IA population. Six patients died during the month following AML chemotherapy, two from a non-IA infection, 3 from AML progression, and one from cerebral hemorrhage.

\section{Diagnostic accuracy of the serum GM assay}

We then analyzed the diagnostic accuracy of serum GM assay for breakthrough IA in our population. Sensitivity and specificity of serum GM test were calculated considering the results of 2297 tests performed on samples obtained from 288 patients. Sensitivity was 


\begin{tabular}{|c|c|c|c|c|}
\hline & & Possible IA-n (\%) & Probable IA-n (\%) & Proven IA-n (\%) \\
\hline & & $12(4.2)$ & $8(2.8)$ & $3(1)$ \\
\hline & Duration of $\mathrm{ANC}<1 \times 10^{9} / \mathrm{L}$ & & & \\
\hline & Median (IQR) & $28(22-34)$ & $39(32-48)$ & $49(21-55)$ \\
\hline & Range & $11 ; 47$ & $22 ; 59$ & $21 ; 55$ \\
\hline & Duration of ANC $<0.5 \times 10^{9} / \mathrm{L}$ & & & \\
\hline & Median (IQR) & $25(21-30)$ & $36(28.5-41)$ & $44(21-51)$ \\
\hline \multirow[t]{8}{*}{ AML } & Range & $10 ; 40$ & $21 ; 48$ & $21 ; 51$ \\
\hline & AML treatment response-n (\%) & & & \\
\hline & CR-CRi & $10(83.3)$ & $4(50)$ & $2(66.7)$ \\
\hline & $\begin{array}{l}\text { Primary or secondary induction } \\
\text { failure }\end{array}$ & $1(8.3)$ & $4(50)$ & $1(33.3)$ \\
\hline & Death before evaluation & $1(8.3)$ & 0 & 0 \\
\hline & Posaconazole duration (days) & & & \\
\hline & Median (IQR) & $13(9-26)$ & $11(8-17.5)$ & $15(7-20)$ \\
\hline & Range & $5 ; 64$ & $5 ; 41$ & $7 ; 20$ \\
\hline \multirow[t]{11}{*}{ Prophylaxis } & $\begin{array}{l}\text { Posaconazole plasma } \\
\text { concentration }(\mathrm{mg} / \mathrm{L})^{\mathrm{a}}\end{array}$ & & & \\
\hline & Median (IQR) & $0.46(0.4-0.65)$ & $0.32(0.2-0.37)$ & $0.18(0.1-0.4)$ \\
\hline & Range & $0.3 ; 1$ & $0.22 ; 2.4$ & $0.1 ; 0.4$ \\
\hline & Clinical signs & & & \\
\hline & Fever & $12(100)$ & $8(100)$ & $3(100)$ \\
\hline & Cough & $3(25)$ & $2(25)$ & $1(33.3)$ \\
\hline & Chest pain & $3(25)$ & 0 & 0 \\
\hline & Dyspnea/crackles & $4(33.3)$ & $3(37.5)$ & 0 \\
\hline & Chest CT signs & & & \\
\hline & Nodule with halo sign & $6(50)$ & $5(62.5)$ & $2(66.7)$ \\
\hline & Nodule without halo & $9(75)$ & $3(37.5)$ & $1(33.3)$ \\
\hline \multirow[t]{9}{*}{ Clinical criteria } & Cavity / Air crescent sign & 0 & 0 & 0 \\
\hline & Ground glass opacities & $5(41.7)$ & $3(37.5)$ & $2(66.7)$ \\
\hline & Alveolar consolidation & $6(50)$ & $1(12.5)$ & $1(33.3)$ \\
\hline & Centrilobular micronodules & $3(25)$ & $2(25)$ & 0 \\
\hline & Bronchoscopy & & & \\
\hline & Performed/indicated-n & $10 / 12$ & $6 / 8$ & $3 / 3$ \\
\hline & Normal & $5(50)$ & $4(66.7)$ & $1(33.3)$ \\
\hline & Inflammation & $5(50)$ & $2(33.3)$ & $2(66.7)$ \\
\hline & Tracheobronchitis $^{\mathrm{b}}$ & $1(10)$ & 0 & $2(66.7)$ \\
\hline
\end{tabular}




\begin{tabular}{|c|c|c|c|c|}
\hline & & Possible IA-n (\%) & Probable IA-n (\%) & Proven IA-n (\%) \\
\hline & & $12(4.2)$ & $8(2.8)$ & $3(1)$ \\
\hline \multirow{12}{*}{$\begin{array}{l}\text { Mycological } \\
\text { criteria }\end{array}$} & Serum GM-ODI c & & & \\
\hline & $>0.5-\mathrm{n}(\%)$ & 0 & $7(87.5)$ & $2(66.7)$ \\
\hline & Mean (Range) & $0.23(0.11 ; 0.46)$ & $1.7(0.23 ; 5.2)$ & $3.0(0.37 ; 7.6)$ \\
\hline & GM-ODI in BAL & & & \\
\hline & Performed/bronchoscopy-n & $8 / 10$ & $5 / 6$ & $2 / 3$ \\
\hline & GM-ODI > 1-n (\%) & 0 & $4(80)$ & $2(100)$ \\
\hline & Mycological test in BAL & & & \\
\hline & Performed/bronchoscopy-n & $10 / 10$ & $6 / 6$ & $3 / 3$ \\
\hline & Positive direct examination & 0 & 0 & $1(33.3)$ \\
\hline & Positive culture & 0 & $1(16.6)$ & $3(100)$ \\
\hline & Identification & none & 1 A. fumigatus & 2 A. fumigatus \\
\hline & & & & $1 \mathrm{~A}$. niger \\
\hline \multirow{2}{*}{$\begin{array}{l}\text { Histological } \\
\text { criteria }\end{array}$} & Examination of sterile material & & & \\
\hline & Lobectomy or bronchial biopsy & 0 & 0 & IFD \\
\hline
\end{tabular}

IA: invasive Aspergillosis, AML: acute myeloid leukemia, IQR: Interquartile range, CR: complete remission, CRi: complete response with incomplete blood recovery, CT: computerized tomography, BAL: bronchoalveolar lavage fluid, GM-ODI: Galactomannan optical density index, IFD: invasive fungal disease, ANC: absolute neutrophil count.

${ }^{a}$ Highest posaconazole plasma concentration obtained by patient before diagnosis has been considered.

${ }^{\mathrm{b}}$ Ulceration, nodule, pseudo membrane, eschar.

${ }^{\mathrm{c}}$ Highest serum GM-ODI value obtained by patient before diagnosis of IA has been considered.

defined by the proportion of patient with IA diagnosed by mycological criteria other than serum GM-ODI (i.e. positive culture or GM-ODI in BAL). Sensitivity of serum GM assay for the detection of probable and proven IA was $81.8 \%{ }^{95 \%} \mathrm{CI}[48.2-97.7]$ and specificity was $96.4 \%{ }^{95 \%} \mathrm{CI}$ [93.5-98.3].

Ten patients were identified as false positives with a median follow-up about 31 months (range 2;62). Median age was 63.5 years, $40 \%$ of male gender, $80 \%$ has an ECOG $<2$ at diagnosis, and one had an history of diabetes mellitus. Median duration of absolute neutrophil count $<1 \times 10^{9} / \mathrm{L}$ or $<0.5 \times 10^{9} / \mathrm{L}$ were both 22 days. Deep neutropenia with absolute neutrophil count lower than $0.1 \times 10^{9} / \mathrm{L}$ for at least 1 day occurred in $50 \%$ of these ten patients. Median duration of posaconazole prophylaxis was 18 days (range 7;27) and median of posaconazole plasma concentration was $1 \mathrm{mg} / \mathrm{L}$ (range $0.3 ; 1.31$ ). Among these ten patients, two $(20 \%)$ developed a fungemia (with Candida glabrata or Geotrichum capitatum) during the neutropenic period following the induction chemotherapy. We did not find well-known risk factors of false positive GM assay such as piperacillin-tazobactam, high-dose immunoglobulin or parenteral nutrition.

To describe the effect of posaconazole on diagnostic accuracy of serum GM assay to detect IA, we considered the highest posaconazole plasma concentration obtained by patient before possible, probable or proven IA diagnosis. Nine among the 124 patients (7.2\%) with posaconazole concentration $<0.5 \mathrm{mg} / \mathrm{L}$ developed an IA: 6 were probable or proven with 5 serum GM positive test (ODI: 5.2, 0.54, 0.98, 1.56, 7.61) and 1 serum GM negative test (ODI: 0.37). Among the 134 patients with posaconazole plasma concentration $\geq 0.5 \mathrm{mg} / \mathrm{L}, 4$ developed an IA (2.9\%) but none of them had a serum GM positive test. Taken together, these results suggest that the diagnostic accuracy of serum GM assay is impaired by high posaconazole concentration.

\section{Variation of serum GM-ODI cut-off positivity}

In view of this decreased diagnostic accuracy of the serum GM assay during effective posaconazole prophylaxis, we wondered whether decreasing the index cutoff value (ICV) could increase the sensitivity of serum GM test during posaconazole prophylaxis. Receiver operator characteristic curves analysis showed that serum GM assay accuracy was still effective to discriminate probable and proven IA (area under the curves $=0.963$ ). We showed an increase of sensitivity from $81.8 \%,{ }^{95 \%} \mathrm{CI}$ [48.2-97.7] to $90.9 \%,{ }^{95 \%} \mathrm{CI}$ [58.7-99.8] when ICV 
Table 3: Univariate and multivariate analyses of factors associated with possible, probable and proven IA under posaconazole prophylaxis

\begin{tabular}{|c|c|c|c|c|c|c|}
\hline & \multicolumn{3}{|c|}{ Univariate analysis } & \multicolumn{3}{|c|}{ Multivariate analysis } \\
\hline & OR & ${ }^{95 \%} \mathbf{C I}$ & $\mathbf{p}$ & OR & ${ }^{95 \%} \mathrm{CI}$ & $\mathbf{p}$ \\
\hline Age $($ years $) \geq 62$ & 0.59 & $0.24-1.40$ & 0.232 & - & - & - \\
\hline Deep neutropenia $\left(\mathrm{ANC}<0.1 \times 10^{9} / \mathrm{L}\right)$ & 1.38 & $0.58-3.25$ & 0.465 & - & - & - \\
\hline Chronic respiratory disease & 4.86 & $1.26-15.81$ & 0.024 & 5.79 & $1.51-22.24$ & 0.0105 \\
\hline Grade IV mucositis & 2.92 & $0.90-8.13$ & 0.072 & - & - & - \\
\hline Posaconazole plasma concentration $\geq 0.5 \mathrm{mg} / \mathrm{L}^{\text {a }}$ & 0.22 & $0.06-0.60$ & 0.002 & 0.22 & $0.07-0.67$ & 0.0082 \\
\hline Duration of $\mathrm{ANC}<0.5 \times 10^{9} / \mathrm{L}>21$ days & 4.37 & $1.59-15.38$ & 0.003 & 4.34 & $1.39-13.57$ & 0.0118 \\
\hline
\end{tabular}

${ }^{\text {a }}$ Highest posaconazole plasma concentration obtained by patient before diagnosis has been considered, ANC: absolute neutrophil count, OR: Odds ratio, CI: confidence interval.

decreased from 0.5 to 0.3 (Figure 1). With this new ICV, the serum GM test became positive for 4 additional patients who had serum GM negative test with a threshold at 0.5 (Supplementary Table 2). One patient had serum GM negative test but proven IA (case 4), 2 patients had clinical and chest-CT scan patterns highly suggestive of IA (case 1 and 3). Finally, the fourth patient (case 2) had a clinical evolution less in favor of IA, despite the isolation of an Aspergillus flavus in sputum sample and a serum GM-ODI at 0.43. Indeed, GM test specificity decreases from $96.4 \%$ with an ICV at 0.5 to $85.9 \%$ with an ICV at 0.3 .

\section{DISCUSSION}

Despite antifungal prophylaxis, IA remains a diagnostic and therapeutic challenge in AML patients [4-6]. In a randomized multicentric study, Cornely et al. demonstrated that posaconazole reduces incidence of IFD and prolongs overall survival of patients with prolonged neutropenia [7]. This study leads to Food and Drug Administration approval of posaconazole for the prophylaxis of IFD in patients who are at high risk of developing these infections. The decrease of serum GM test sensitivity by antifungal prophylaxis has been demonstrated by Marr et al. in 2005 in patients that received chemotherapy or allogenic hematopoietic stem cell transplant for various hematological malignancies, but posaconazole was not used in this work [8]. So, the current observational and retrospective study was focused on a homogeneous population of AML patients receiving induction chemotherapy with posaconazole prophylaxis, in order to analyze breakthrough IA and diagnostic accuracy of GM assay.

Incidence of IA in this studied population was $8 \%$, with $3.8 \%$ of probable and proven IA. This incidence is higher than the one described in prospective randomized study by Cornely et al. [7], but consistent with the incidence in real-life studies previously reported in AML patients [4, 9-12]. We found exclusively pulmonary IA with poor clinical symptoms. Fever was the sole symptom in $20 \%$ of IA patients. Those limited clinical manifestations could possibly be explained by antifungal prophylaxis. This point has already been described by Peterson et al. who reported IA-related clinical symptoms in $31 \%$ and $4 \%$, without and with antifungal prophylaxis, respectively [13]. We found that prolonged neutropenia and low posaconazole plasma concentration were factors associated with high risk of IA $[14,15]$, but also chronic respiratory comorbidity. In such a context, patients with chronic respiratory disease could be screened for Aspergillus colonization before chemotherapy.

Antifungal prophylaxis is known to reduce the fungal load in animal models [16, 17] and serum GM level is known to be correlated to this fungal load [3], particularly in neutropenic patients: posaconazole could reduce serum GM load and might impair diagnostic accuracy of the test. In the paper from Marr et al., specificity of serum GM test remained unchanged but the authors showed a sensitivity for detection of probable and proven IA in control arm and treatment arm about $89 \%$ and $52 \%$, respectively [8]. In the current study, all patients received antifungal prophylaxis by posaconazole oral suspension and sensitivity was $81.8 \%$ for a specificity about $96.4 \%$. Moreover, we found that none patient with IA and posaconazole plasma concentration $\geq 0.5 \mathrm{mg} / \mathrm{L}$ had a serum GM positive test. We then tested a lower ICV and found an increased sensitivity of the serum GM test for probable and proven IA diagnosis. These results suggesting that posaconazole decreased the diagnostic accuracy of serum GM assay have been obtained in a specific population and should be taken with caution in other clinical situations. Indeed, the goal of an efficient prophylaxis is to lower the prevalence of a disease but the efficiency of a test is also highly dependent of this prevalence and spectrum of the disease $[18,19]$. 
Table 4: Treatment and evolution of IA patients

Possible IA

$\mathrm{n}=12$

6

3

11

$7(1 ; 12)$

$6(3 ; 9)$

$100(2 ; 235)$

Probable and proven IA

Antifungal treatment-n a

Liposomal amphotericin B

Caspofungin

Voriconazole

Duration of treatment (days)-Mean (range)

Liposomal amphotericin B

Caspofungin

Voriconazole

Causes of Voriconazole discontinuation-n ${ }^{\text {b }}$

Complete response

10

0

1

$n=11$

Failure

Death

Clinical Response (days)-Mean (range)

Time to apyrexia

$6(1 ; 14)$

$11(1 ; 19)$

TDM evaluation-n

${ }^{a}$ Each patient can receive several treatments, ${ }^{b}$ One patient with possible IA did not receive voriconazole, but only liposomal amphotericin B, IA: invasive aspergillosis.

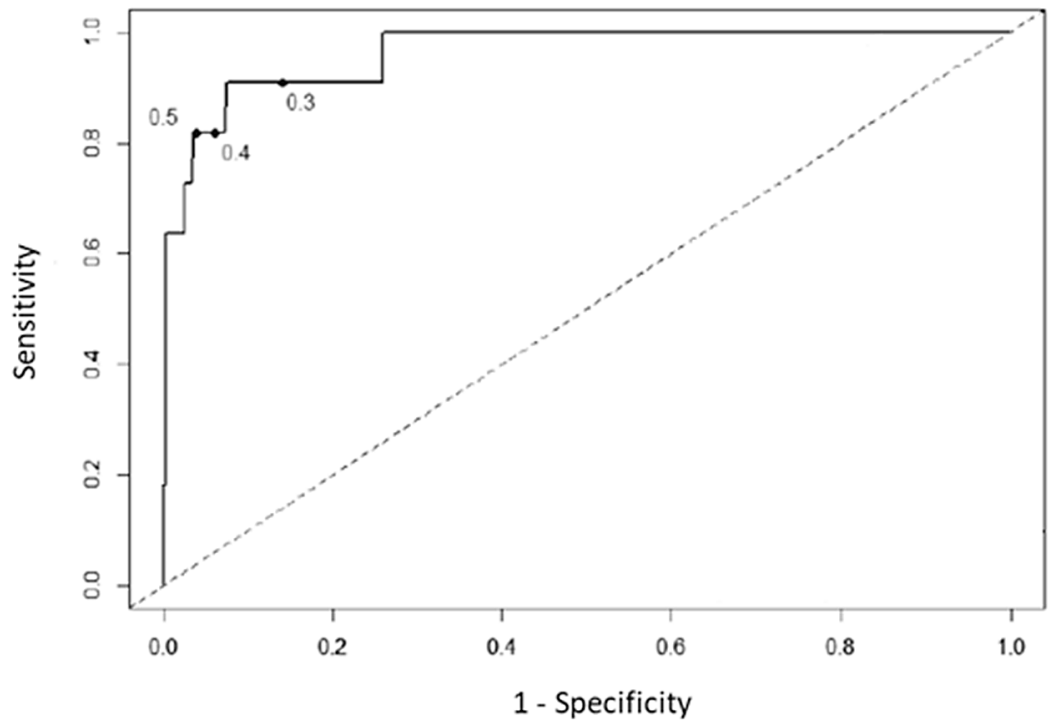

Figure 1: Receiver operator characteristic curves, using multiple index cutoff values to define positivity. The index cutoff value defining positivity decreases from the highest to lowest value as the curve moves from left to right. 
This is a critical point since posaconazole is now available in tablet formulation that has been developed to optimize bioavailability. Cornely et al. indeed recently showed that with this tablet formulation, the average concentration was superior to $0.5 \mathrm{mg} / \mathrm{L}$ for $99 \%$ of the patients [20]. Another study recently described posaconazole levels in real-life patients: the mean of posaconazole plasma concentration was $1.32 \mathrm{mg} / \mathrm{L}$ versus $0.81 \mathrm{mg} / \mathrm{L}$, under tablet or oral suspension formulations, respectively [21].

Being aware of the drawbacks of our study design, we are convinced that our data make a valuable contribution in the field of IA risk management in AML patients during neutropenic period following induction chemotherapy. This study displays undoubtedly several bias due to its retrospective design and lack of systematic posaconazole plasma dosage (even if 90\% had at least one dosage). We analyzed 2297 sera allowing strong multivariate analysis of risk factors associated with IA incidence. Whether these findings also translate into current practice with tablet formulation cannot be answered by our data but should be addressed by a prospective, multicentric study in the light of these results.

At our knowledge, posaconazole is not very prone to pharmacogenetic variability due to its low metabolism unlike voriconazole. If voriconazole is substrate and inhibitor of many isoforms of cytochrome P450, posaconazole is an inhibitor but only a weak substrate [22]. Actually, absorption is clearly the rate-limiting step for pharmacokinetics of posaconazole oral suspension. Other treatment interfere with results [23], particularly proton-pump inhibitors [24]. No data support interaction at distribution and elimination phases of pharmacokinetics and its metabolization is weak: the only drugs that could have an effect on these points are rifampicin and phenytoin that were not prescribed in these patients [25].

The last Infectious Diseases Society of America practice guidelines do not recommend anymore serum GM screening for asymptomatic patients receiving efficient mold-active antifungal prophylaxis [26]. The current study indeed suggests that AML patients with high posaconazole plasma concentration do not benefit from this screening policy. Such levels are mostly achieved with posaconazole tablet formulation, the galenic formulation currently used. Nevertheless, invasive aspergillosis remains a life-threatening infection that needs an early diagnosis. In our opinion, the IDSA recommendations should be taken with caution, only for patients with posaconazole plasma concentration $\geq 0.5 \mathrm{mg} / \mathrm{L}$ appended to a rigorous diagnostic-driven approach. The feasibility of this diagnostic-driven strategy has recently been assessed in a prospective study in high-risk hematology patients. The incidence of invasive fungal disease, fungalrelated death and all-cause mortality rates were similar in a classical approach and in a diagnostic-driven strategy. However, only hundred patients were included in the diagnostic-driven strategy arm, oral solution and not tablet formulation of posaconazole was used, and no data on posaconazole plasma concentration were submitted [27]. Finally, other diagnostic tools could support new screening strategies. Even if Aspergillus polymerase chain reaction is diminished under antifungal mold prophylaxis [28], its combination with serum GM assay have shown promising results [29, 30].

\section{MATERIALS AND METHODS}

\section{Patients and prophylactic strategies}

Selection criteria for this retrospective study were a diagnosis of AML according to WHO classification [31] between May 1st, 2008 and November 30, 2015 in the Department of Hematology and Cell Therapy of the Bordeaux University Hospital, > 17 years of age, without previous history of allogeneic or autologous hematopoietic stem cell transplant. Cytogenetic risk classification was defined according to the British Medical Research Council classification [32]. Patients have been included in the current study if they received at least 5 days of posaconazole prophylaxis (200 $\mathrm{mg}$ three times a day), exclusively by oral suspension. Posaconazole plasma concentration was monitored biweekly, started after 5 days of treatment [33]. If concentration was lower than 0.7 $\mathrm{mg} / \mathrm{L}$, posaconazole was increased to $200 \mathrm{mg}$ four times a day. Written informed consents have been obtained from all patients in accordance with the Declaration of Helsinki, allowing the collection of clinical and biological data in an anonymized database, registered at the Commission Nationale Informatique et Libertés under N 1777604.

\section{Laboratory diagnosis of IFD}

Diagnostic procedures for the diagnosis of IFD routinely used galactomannan enzyme immunoassay in serum, bronchoalveolar lavage (BAL), and cerebrospinal fluid (CSF) besides histology, direct examination and culture on clinical specimens according to standard method [34]. Briefly, identification of fungi was done using classical phenotypically methods until implementation of matrix-assisted laser desorption/ionization time-of-flight mass spectrometry (MALDI-TOF MS, Microflex, Bruker Daltonics): yeasts were identified using MALDI Biotyper V1.3 Software (Bruker Daltonics) since April 2013 and filamentous fungi were identified at the species level using an extended reference spectra library [35] since October 2014. Mucormycosis diagnosis was carried out using PCR on serum in the Mycology Laboratory of Besancon University Hospital [36]. Serum GM tests were performed twice a week until neutropenia recovery, yielding a total of 2297 collected sera. Galactomannan detection was performed using the Platelia ${ }^{\mathrm{TM}}$ Aspergillus Ag kit (BioRad Laboratories, Marnes-la-Coquette, France) according 
to the manufacturer's instructions. Serum, BAL and CSF were treated under a class 2 biological safety cabinet. Positive GM tests were controlled on the same sample and always verified on another sample. GM assay in BAL were performed in duplicate.

\section{Monitoring of posaconazole plasma concentration}

From December 1st, 2008 to February 15, 2010, the posaconazole plasma concentration was performed by highperformance liquid chromatography (limit of detection/ $\mathrm{LOD}=0.02 \mu \mathrm{g} / \mathrm{mL}$ and limit of quantification $/ \mathrm{LOQ}=0.05$ $\mu \mathrm{g} / \mathrm{ml}$ ) assay developed for a simultaneous determination of systemic azoles (fluconazole, posaconazole, voriconazole, itraconazole and its metabolite hydroxyl-itraconazole, and ketoconazole) as previously published [37]. Since February 15,2010 , this posaconazole plasma concentration analysis is coupled with tandem mass spectrometry.

\section{Diagnostic strategy and EORTC/MSG 2008 sub group assignment}

AML patient's characteristics are collected in an ongoing prospective database of the Department of Clinical Hematology and Cell Therapy. The clinical records of patients are evaluated to determine presence or absence of IA, date of diagnosis, date of clinical onset and receipt of antifungal therapies. Date of diagnosis was the earliest date among the day of suggestive computerized tomography (CT) scan or the day of microbiological or histopathological allowing diagnosis for probable and proven IA. The diagnosis of IFD was made in accordance with the revised EORTC/MSG definitions published in 2008 [2]. According to the above definitions, the whole cohort has host factor criteria with recent history of neutropenia $\left(<0.5 \times 10^{9}\right.$ neutrophils/L for $>10$ days). Diagnosis of possible IA was made according to clinical criteria of lower respiratory tract fungal disease on CTscan, trachea-bronchitis on bronchoscopic analysis, without mycological criteria. Diagnosis of probable IA was made from the documentation of one of the clinical or radiological findings described above associated with mycological criteria by isolation of mold in sputum, BAL or bronchial brush, or serum GM-ODI ICV $>0.5$ or BAL GM-ODI ICV $>1$. Diagnosis of proven IFD was retain by demonstrating fungus in diseased tissue (lobectomy or bronchial biopsy). All chest-CT scans have been routinely analyzed by a specialized radiologist (VL) and specifically reviewed for the study by an experienced pulmonary physician (EB) who was unaware of both clinical and biological results. CT images have been specifically examined in each lung and following radiological end points have been collected: nodule with or without halo sign, cavity / air crescent sign, ground glass opacities, alveolar consolidation, centrilobular micronodules, bronchiectases, pleural effusion, calcifications, and pneumothorax. Classical EORTC/MSG 2008 definitions were used for descriptive analysis of breakthrough IFD.

\section{Statistical analysis}

Diagnostic accuracy of serum GM-ODI was estimated by computing and presenting as sensitivity and specificity under the conditions of the serum GM-ODI ICV of $0.3,0.4$ and 0.5 with their $95 \%$ confidence interval (CI). We used standard methods for binomial proportions to calculate the CI. The receiver operating characteristic (ROC) curve was calculated and the area under the curves was reported. We estimated association between explanatory variables and IA (binary dependent variable) by performing a multivariable logistic regression. Variables and interaction terms associated $(\mathrm{p}<0.20)$ with IA status were then included in a multivariate logistic regression model $(\mathrm{p}<0.20)$. The analyses were performed using SAS 9.3 (SAS institute Inc, Cary, NC) and R 3.2.2 [38].

\section{Abbreviations}

AML: Acute Myeloid Leukemia; BAL: BronchoAlveolar Lavage; CT: Computerized tomography; EORTC/MSG: European Organization for Research and Treatment of Cancer/Mycoses Study Group; GM: Galactomannan; GM-ODI: Galactomannan Optical Density Index; IA: Invasive Aspergillosis; ICV: Index Cutoff Value; IFD: Invasive Fungal Disease; IQR: Interquartile range; OR: Odds ratio.

\section{Author contributions}

Designed research and analyzed data, C.C, F.G, E.B, V.S, C.L, N.K, P.-Y.D; Data collection, C.C, F.G, E.B, V.S, N.K, E.F, P.-Y.D; Patients management, A.P, T.L, E.F, A.B, S.V, R.T, E.B, V.L., C.C, P.-Y.D; Posaconazole plasma concentration, S.B, V.S, D.B; Galactomannan Enzyme Immunoassay, F.G, I.A, L.D; Original Draft F.G, E.B, P.Y.D; Comments on the research direction and edition of the manuscript A.P., M.T.L, N.M; Writing - Review \& Edition, C.C, F.G, E.B, V.S, P.-Y.D.; Made Figures, C.C, N.K.

\section{ACKNOWLEDGMENTS}

We thank Pr A. Bergeron and Pr. L. Delhaes for the critical reading of the manuscript.

\section{CONFLICTS OF INTEREST}

The authors declare no conflicts of interest.

\section{FUNDING}

Not applicable. 


\section{REFERENCES}

1. Döhner H, Estey EH, Amadori S, Appelbaum FR, Büchner T, Burnett AK, Dombret H, Fenaux P, Grimwade D, Larson RA, Lo-Coco F, Naoe T, Niederwieser D, et al. Diagnosis and management of acute myeloid leukemia in adults: recommendations from an international expert panel, on behalf of the European LeukemiaNet. Blood. 2010; 115: 453-74. https://doi.org/10.1182/blood-2009-07-235358.

2. De Pauw B, Walsh TJ, Donnelly JP, Stevens DA, Edwards JE, Calandra T, Pappas PG, Maertens J, Lortholary O, Kauffman CA, Denning DW, Patterson TF, Maschmeyer $\mathrm{G}$, et al. Revised definitions of invasive fungal disease from the European Organization for Research and Treatment of Cancer/Invasive Fungal Infections Cooperative Group and the National Institute of Allergy and Infectious Diseases Mycoses Study Group (EORTC/MSG) Consensus Group. Clin Infect Dis. 2008; 46: 1813-21. https://doi.org/10.1086/588660.

3. Mennink-Kersten MA, Donnelly JP, Verweij PE. Detection of circulating galactomannan for the diagnosis and management of invasive aspergillosis. Lancet Infect Dis. 2004; 4: 349-57. https://doi.org/10.1016/S1473-3099(04)01045-X.

4. Pagano L, Caira M, Candoni A, Offidani M, Fianchi L, Martino B, Pastore D, Picardi M, Bonini A, Chierichini A, Fanci R, Caramatti C, Invernizzi R, et al. The epidemiology of fungal infections in patients with hematologic malignancies: the SEIFEM-2004 study. Haematologica. 2006; 91: 1068-75.

5. Pagano L, Caira M, Candoni A, Offidani M, Martino B, Specchia G, Pastore D, Stanzani M, Cattaneo C, Fanci R, Caramatti C, Rossini F, Luppi M, et al. Invasive aspergillosis in patients with acute myeloid leukemia: a SEIFEM-2008 registry study. Haematologica. 2010; 95: 644-50. https://doi. org/10.3324/haematol.2009.012054.

6. Lortholary O, Gangneux JP, Sitbon K, Lebeau B, de Monbrison F, Le Strat Y, Coignard B, Dromer F, Bretagne $\mathrm{S}$, French Mycosis Study Group. Epidemiological trends in invasive aspergillosis in France: the SAIF network (20052007). Clin Microbiol Infect. 2011; 17: 1882-9. https://doi. org/10.1111/j.1469-0691.2011.03548.x.

7. Cornely OA, Maertens J, Winston DJ, Perfect J, Ullmann AJ, Walsh TJ, Helfgott D, Holowiecki J, Stockelberg D, Goh YT, Petrini M, Hardalo C, Suresh R, et al. Posaconazole vs. fluconazole or itraconazole prophylaxis in patients with neutropenia. N Engl J Med. 2007; 356: 348-59. https://doi. org/10.1056/NEJMoa061094.

8. Marr KA, Laverdiere M, Gugel A, Leisenring W. Antifungal therapy decreases sensitivity of the Aspergillus galactomannan enzyme immunoassay. Clin Infect Dis. 2005; 40: 1762-9. https://doi.org/10.1086/429921.

9. Michallet M, Sobh M, Morisset S, Kraghel S, Nicolini FE, Thomas X, Bienvenu AL, Picot S, Nicolle MC, Vanhems P. Risk factors for invasive aspergillosis in acute myeloid leukemia patients prophylactically treated with posaconazole.
Med Mycol. 2011; 49: 681-7. https://doi.org/10.3109/13693 786.2011 .557668 .

10. Vehreschild JJ, Rüping MJ, Wisplinghoff H, Farowski F, Steinbach A, Sims R, Stollorz A, Kreuzer KA, Hallek M, Bangard C, Cornely OA. Clinical effectiveness of posaconazole prophylaxis in patients with acute myelogenous leukaemia (AML): a 6 year experience of the Cologne AML cohort. J Antimicrob Chemother. 2010; 65: 1466-71. https:// doi.org/10.1093/jac/dkq121.

11. Duarte RF, Sánchez-Ortega I, Cuesta I, Arnan M, Patiño B, Fernández de Sevilla A, Gudiol C, Ayats J, Cuenca-Estrella M. Serum galactomannan-based early detection of invasive aspergillosis in hematology patients receiving effective antimold prophylaxis. Clin Infect Dis. 2014; 59: 1696-702. https://doi.org/10.1093/cid/ciu673.

12. Biehl LM, Vehreschild JJ, Liss B, Franke B, Markiefka B, Persigehl T, Bücker V, Wisplinghoff H, Scheid C, Cornely OA, Vehreschild MJ. A cohort study on breakthrough invasive fungal infections in high-risk patients receiving antifungal prophylaxis. J Antimicrob Chemother. 2016; 71:2634-41. https://doi.org/10.1093/jac/dkw199.

13. Peterson L, Ostermann J, Rieger H, Ostermann H, Rieger CT. Posaconazole prophylaxis - impact on incidence of invasive fungal disease and antifungal treatment in haematological patients. Mycoses. 2013; 56: 651-8. https://doi.org/10.1111/ myc. 12086.

14. Mühlemann K, Wenger C, Zenhäusern R, Täuber MG. Risk factors for invasive aspergillosis in neutropenic patients with hematologic malignancies. Leukemia. 2005; 19: 545-50. https://doi.org/10.1038/sj.leu.2403674.

15. Nivoix $Y$, Velten $M$, Letscher-Bru V, Moghaddam A, Natarajan-Amé S, Fohrer C, Lioure B, Bilger K, Lutun P, Marcellin L, Launoy A, Freys G, Bergerat JP, et al. Factors associated with overall and attributable mortality in invasive aspergillosis. Clin Infect Dis. 2008; 47: 1176-84. https://doi. org/10.1086/592255.

16. Becker MJ, de Marie S, Fens MH, Verbrugh HA, BakkerWoudenberg IA. Effect of amphotericin B treatment on kinetics of cytokines and parameters of fungal load in neutropenic rats with invasive pulmonary aspergillosis. J Antimicrob Chemother. 2003; 52: 428-34. https://doi. org/10.1093/jac/dkg367.

17. Petraitiene R, Petraitis V, Groll AH, Sein T, Piscitelli S, Candelario M, Field-Ridley A, Avila N, Bacher J, Walsh TJ. Antifungal activity and pharmacokinetics of posaconazole (SCH 56592) in treatment and prevention of experimental invasive pulmonary aspergillosis: correlation with galactomannan antigenemia. Antimicrob Agents Chemother. 2001; 45: 857-69. https://doi.org/10.1128/ AAC.45.3.857-869.2001.

18. Pfeiffer CD, Fine JP, Safdar N. Diagnosis of invasive aspergillosis using a galactomannan assay: a metaanalysis. Clin Infect Dis. 2006; 42: 1417-27. https://doi. org/10.1086/503427. 
19. Leeflang MM, Debets-Ossenkopp YJ, Visser CE, Scholten RJ, Hooft L, Bijlmer HA, Reitsma JB, Bossuyt PM, Vandenbroucke-Grauls CM. Galactomannan detection for invasive aspergillosis in immunocompromized patients. Cochrane Database Syst Rev. 2008; 4: CD007394. https:// doi.org/10.1002/14651858.CD007394.

20. Cornely OA, Duarte RF, Haider S, Chandrasekar P, Helfgott D, Jiménez JL, Candoni A, Raad I, Laverdiere M, Langston A, Kartsonis N, Van Iersel M, Connelly N, et al. Phase 3 pharmacokinetics and safety study of a posaconazole tablet formulation in patients at risk for invasive fungal disease. J Antimicrob Chemother. 2016; 71: 718-26. https://doi. org/10.1093/jac/dkv380.

21. Duarte RF, López-Jiménez J, Cornely OA, Laverdiere M, Helfgott D, Haider S, Chandrasekar P, Langston A, Perfect J, Ma L, van Iersel ML, Connelly N, Kartsonis N, et al. Phase 1b Study of New Posaconazole Tablet for Prevention of Invasive Fungal Infections in High-Risk Patients with Neutropenia. Antimicrob Agents Chemother. 2014; 58: 5758-65. https:// doi.org/10.1128/AAC.03050-14

22. Amsden JR, Gubbins PO. Pharmacogenomics of triazole antifungal agents: implications for safety, tolerability and efficacy. Expert Opin Drug Metab Toxicol. 2017; 13: 1135 46. https://doi.org/10.1080/17425255.2017.1391213.

23. Lipp HP. Clinical pharmacodynamics and pharmacokinetics of the antifungal extended-spectrum triazole posaconazole: an overview. Br J Clin Pharmacol. 2010; 70: 471-80. https://doi. org/10.1111/j.1365-2125.2010.03680.x.

24. Krishna G, AbuTarif M, Xuan F, Martinho M, Angulo D, Cornely OA. Pharmacokinetics of oral posaconazole in neutropenic patients receiving chemotherapy for acute myelogenous leukemia or myelodysplastic syndrome. Pharmacotherapy. 2008; 28: 1223-32. https://doi.org/10.1592/ phco.28.10.1223.

25. Lipp HP. Posaconazole: clinical pharmacokinetics and drug interactions. Mycoses. 2011; 54 Suppl 1: 32-8. https://doi. org/10.1111/j.1439-0507.2010.01984.x.

26. Patterson TF, Thompson GR, Denning DW, Fishman JA, Hadley S, Herbrecht R, Kontoyiannis DP, Marr KA, Morrison VA, Nguyen MH, Segal BH, Steinbach WJ, Stevens DA, et al. Practice Guidelines for the Diagnosis and Management of Aspergillosis: 2016 Update by the Infectious Diseases Society of America. Clin Infect Dis. 2016; 63: e1-60. https://doi. org/10.1093/cid/ciw326.

27. Duarte RF, Sánchez-Ortega I, Arnan M, Patiño B, Ayats J, Sureda A, Cuenca-Estrella M. Serum galactomannan surveillance may be safely withdrawn from antifungal management of hematology patients on effective antimold prophylaxis: a pilot single-center study. Bone Marrow Transplant. 2017; 52: 326-9. https://doi.org/10.1038/ bmt.2016.279.

28. Springer J, Lackner M, Nachbaur D, Girschikofsky M, Risslegger B, Mutschlechner W, Fritz J, Heinz WJ, Einsele H, Ullmann AJ, Löffler J, Lass-Flörl C. Prospective multicentre PCR-based Aspergillus DNA screening in high-risk patients with and without primary antifungal mould prophylaxis. Clin Microbiol Infect. 2016; 22: 80-6. https://doi.org/10.1016/j. cmi.2015.09.009.

29. Aguado JM, Vázquez L, Fernández-Ruiz M, Villaescusa T, Ruiz-Camps I, Barba P, Silva JT, Batlle M, Solano C, Gallardo D, Heras I, Polo M, Varela R, et al. Serum Galactomannan Versus a Combination of Galactomannan and Polymerase Chain Reaction-Based Aspergillus DNA Detection for Early Therapy of Invasive Aspergillosis in HighRisk Hematological Patients: A Randomized Controlled Trial. Clin Infect Dis. 2015; 60: 405-14. https://doi.org/10.1093/cid/ ciu833.

30. Arvanitis M, Anagnostou T, Mylonakis E. Galactomannan and Polymerase Chain Reaction-Based Screening for Invasive Aspergillosis Among High-Risk Hematology Patients: A Diagnostic Meta-analysis. Clin Infect Dis. 2015; 61: 1263-72. https://doi.org/10.1093/cid/civ555.

31. Vardiman JW, Thiele J, Arber DA, Brunning RD, Borowitz MJ, Porwit A, Harris NL, Le Beau MM, Hellström-Lindberg E, Tefferi A, Bloomfield CD. The 2008 revision of the World Health Organization (WHO) classification of myeloid neoplasms and acute leukemia: rationale and important changes. Blood. 2009; 114: 937-51. https://doi.org/10.1182/ blood-2009-03-209262.

32. Grimwade D, Hills RK, Moorman AV, Walker H, Chatters S, Goldstone AH, Wheatley K, Harrison CJ, Burnett AK, National Cancer Research Institute Adult Leukaemia Working Group. Refinement of cytogenetic classification in acute myeloid leukemia: determination of prognostic significance of rare recurring chromosomal abnormalities among 5876 younger adult patients treated in the United Kingdom Medical Research Council trials. Blood. 2010; 116: 354-65. https:// doi.org/10.1182/blood-2009-11-254441.

33. Jang SH, Colangelo PM, Gobburu JV. Exposure-response of posaconazole used for prophylaxis against invasive fungal infections: evaluating the need to adjust doses based on drug concentrations in plasma. Clin Pharmacol Ther. 2010; 88: 115-9. https://doi.org/10.1038/clpt.2010.64.

34. Arendrup MC, Bille J, Dannaoui E, Ruhnke M, Heussel CP, Kibbler C. ECIL-3 classical diagnostic procedures for the diagnosis of invasive fungal diseases in patients with leukaemia. Bone Marrow Transplant. 2012; 47: 1030-45. https://doi.org/10.1038/bmt.2011.246.

35. Becker PT, de Bel A, Martiny D, Ranque S, Piarroux R, Cassagne C, Detandt M, Hendrickx M. Identification of filamentous fungi isolates by MALDI-TOF mass spectrometry: clinical evaluation of an extended reference spectra library. Med Mycol. 2014; 52: 826-34. https://doi. org/10.1093/mmy/myu064.

36. Millon L, Larosa F, Lepiller Q, Legrand F, Rocchi S, Daguindau E, Scherer E, Bellanger AP, Leroy J, Grenouillet F. Quantitative polymerase chain reaction detection of circulating DNA in serum for early diagnosis of mucormycosis in immunocompromised patients. Clin Infect Dis. 2013; 56: e95-101. https://doi.org/10.1093/cid/cit094. 
37. Gordien JB, Pigneux A, Vigouroux S, Tabrizi R, Accoceberry I, Bernadou JM, Rouault A, Saux MC, Breilh D. Simultaneous determination of five systemic azoles in plasma by high-performance liquid chromatography with ultraviolet detection. J Pharm Biomed Anal. 2009; 50: 932-8. https://doi. org/10.1016/j.jpba.2009.06.030.

38. R Core Team (2015). R: A language and environment for statistical computing. R Foundation for Statistical, Computing, Vienna, Austria. URL https:/www.R-project.org/. 